\title{
QUISTE OVARICO NEONATAL: DIAGNÓSTICO PRENATAL Y MANEJO POST NATAL LAPAROSCÓPICO
}

\author{
Jackelyne Alvarado ${ }^{1}$, Fernando Ayque ${ }^{2}$, Alan Chipana $\mathrm{P}^{3}$.
}

\begin{abstract}
RESUMEN
Los quistes ováricos son la tumoración abdominal más frecuente en la etapa neonatal. Pueden presentarse desde casos asintomáticos hasta pacientes con quistes complicados con sangrado; ascitis, hemorrágica por ruptura del quiste, peritonitis y torsión. El diagnóstico prenatal mediante la ultrasonografía es fundamental para el manejo oportuno de las pacientes.

Existen diferentes alternativas de tratamiento que va desde observación, punción percutánea con guía ecográfica hasta el abordaje laparoscópico que dependerá del patrón y diámetro del quiste, siempre teniendo presente la preservación de las gónadas para asegurar el desarrollo en la pubertad y la fertilidad a futuro.
\end{abstract}

Se presenta el caso de una niña de 45 días de vida que se muestra el diagnóstico prenatal y la aparición de un quiste complejo en uno de sus controles ecográficos, el cual es resuelto de manera laparoscópica.

Palabras clave: Quiste ovárico; Neonatal; Laparoscopía (Fuente: DeCS BIREME).

\section{NEONATAL OVARIAN CYST: PRENATAL DIAGNOSIS AND POSTNATAL LAPAROSCOPIC MANAGEMENT}

\begin{abstract}
Ovarian cysts are the most frequent abdominal tumor in the neonatal stage. They can occur from asymptomatic cases to patients with complicated cysts with bleeding; Ascites, hemorrhagic rupture of the cyst, peritonitis and torsion. Prenatal diagnosis using ultrasonography is fundamental for the timely management of patients.

There are different treatment alternatives ranging from observation, percutaneous puncture with ultrasound guidance to the laparoscopic approach that will depend on the pattern and diameter of the cyst, always keeping in mind the preservation of the gonads to ensure development in puberty and future fertility.
\end{abstract}

We present the case of a 45-day-old girl who shows the prenatal diagnosis and the appearance of a complex cyst in one of her ultrasound controls, which is solved laparoscopically.

Key words: Ovarian cyst; Neonatal; Laparoscopy (Source: MeSH NLM).

\section{INTRODUCCIÓN}

En la actualidad todavía hay controversia acerca del mejor tratamiento para el quiste ovárico neonatal, la conducta a realizar dependerá de su patrón ecográfico y de diámetro del quiste; y de acuerdo a estos criterios serán consideradas simples y complejos o complicados y se decidirá la conducta a seguir.

Las masas anexiales incluyen quistes, neoplasias otorsiones de anexo normal localizadas en los ovarios o trompas. En el recién nacido es difícil establecer el diagnóstico precoz en forma clínica, ya que su sintomatología es tardía e inespecífica, por eso es de gran utilidad los estudios por imágenes en especial la ecografía.

El objetivo de esta presentación es mostrar el diagnóstico prenatal de quiste ovárico y su manejo por cirugía mínimamente invasiva post natal.

\section{DESCRIPCIÓN DEL CASO CLÍNICO}

Presentamos el caso de una recién nacida (RN), sexo femenino, de 15 días de nacida, a término, de 3676 gr al nacer, actualmente asintomática que acude a consultorio externo de cirugía pediátrica derivada por pediatría por presentar como antecedente ecografía fetal de 34 semanas: 2 tumoraciones intrabdominales, imagen hiperecogénica de bordes definidos de 20,2×20×15 mm en fosa iliaca derecha y $33 \times 30 \times 30 \mathrm{~mm}$ en fosa iliaca izquierda, sin otras alteraciones anatómicas, confirmadas según resonancia magnética nuclear (RMN) fetal la presencia de dichos quistes subhepáticas que la habían catalogado como probable Quiste de Mesenterio. Durante la anamnesis madre indica que al nacer le realizan ecografía abdominal (figura 1) donde se confirma la presencia de lesión quística, al encontrarse la paciente sin síntomas deciden manejo conservador con control por consultorio. En la ecografía de nacimiento confirma la

\footnotetext{
Jefa del Servicio de Cirugía Neonatal. Instituto Nacional Materno- Perinatal. Lima-Perú.

Médico Asistente de Cirugía Neonatal. Instituto Nacional Materno- Perinatal. Lima-Perú.

Médico Residente de Cirugía Pediátrica de $3^{\circ}$ año. Universidad Nacional Federico Villarreal. Sede Instituto Nacional MaternoPerinatal. Lima-Perú
}

Recibido: 12-06-17 Aprobado: 30-06-17 
presencia de tumoración quística de $55 x 44 \mathrm{~mm}$, volumen 42 cc. y solicitan estudio de tomografía espiral multicorte (TEM) (figura 2) para realizar en forma ambulatoria. El examen físico es normal, en el abdomen no se logra palpar masas ni tumoraciones.

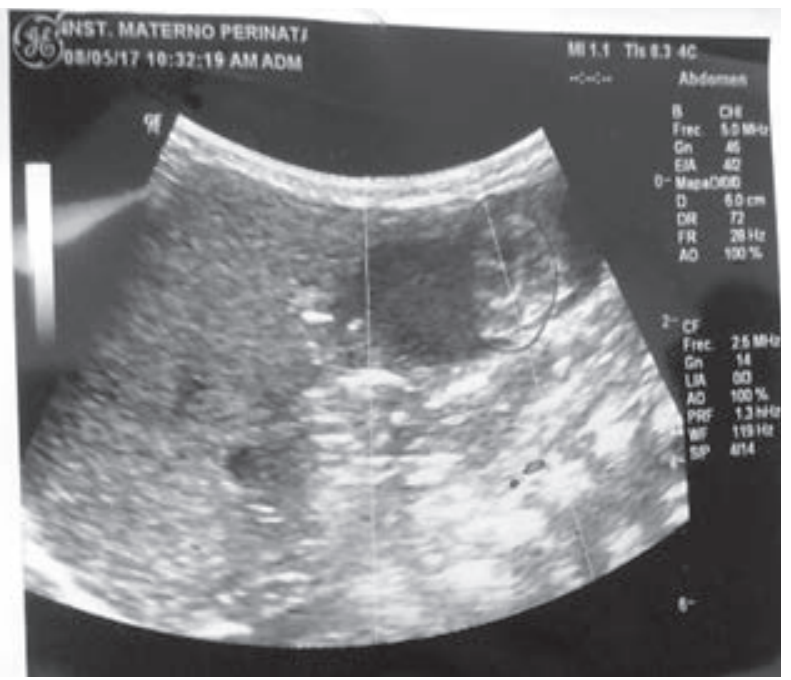

Figura 1. Ecografía abdominal.

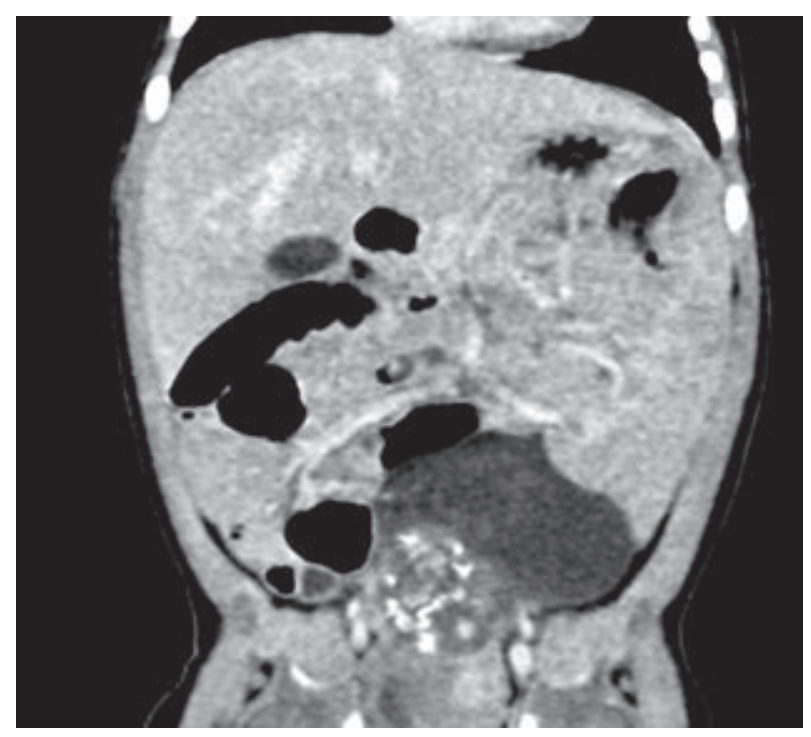

Figura 2. Tomografía espiral multicorte (TEM).

Se le indica ecografía abdominal (figura 3) evidenciando ovario izquierdo. Volumen=9,4 cc, con múltiples micro quistes de 3 a $4 \mathrm{~mm}$. Anexo derecho con presencia de tumoración compleja de $50 \times 40 \mathrm{~mm}$ volumen=42,5 cc, quiste complejo en el que se muestra vegetación de $33 \times 7 \mathrm{~mm}(5 \mathrm{cc})$ y contenido denso que muestra nivel, y en la TEM realizada se evidencia presencia de quiste compatible con quiste de ovario. Al revisar y comparar con imágenes anteriores Se diagnóstica quiste de ovario complejo neonatal probablemente desde la etapa fetal. Se decide su hospitalización para tratamiento quirúrgico,

Se le realizaron exámenes laboratoriales hematológicos de rutina como hemograma y pruebas de función renal

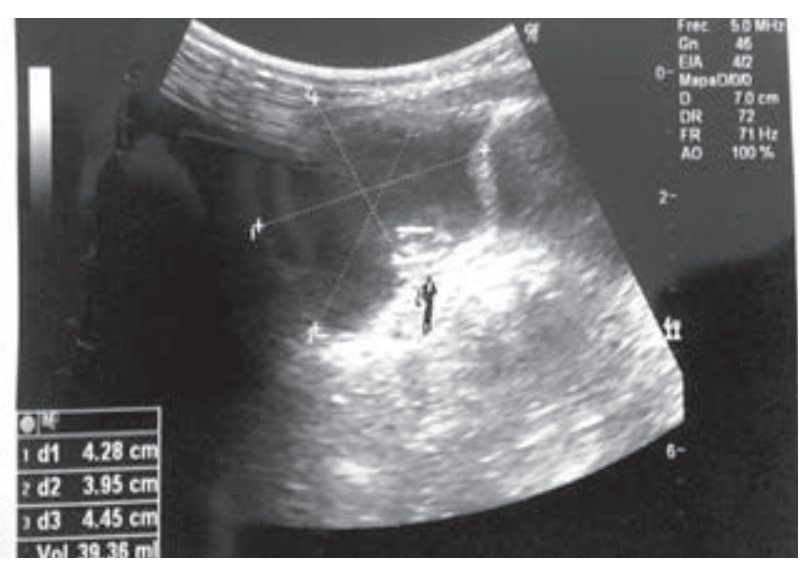

Figura 3. Ecografía abdominal.

que fueron normales. Además se realizó exámenes bioquímica que fueron normales.

Para el tratamiento se realizó mediante abordaje laparoscópico; no hubo necesidad de preparación intestinal (12), los hallazgos fueron un quiste anexial derecho hemorrágico de $5 \times 4 \mathrm{~cm}$ con pedículo torcido (figura 4). $Y$ múltiples quistes de aproximadamente $1 \mathrm{~cm}$ en ovario izquierdo, resto de órganos dentro de lo normal. La presión de CO2 utilizada para la creación del neumoperitoneo oscilo entre 5 y $8 \mathrm{~mm}$ hg. El primer trocar se insertó a nivel umbilical (figura 5). Utilizamos una óptica de $5 \mathrm{~mm}$ y 0 grados para el tratamiento del quiste. El segundo trocar de $3 \mathrm{~mm}$ se colocó en el flanco izquierdo, se introdujo de una pinza atraumática a través del mismo la cual permitió la exploración de la cavidad y confirmación del diagnóstico. El pedículo se electro fulguró utilizando corriente bipolar y se extrajo la pieza a través del ombligo, previa punción evacuatoria. La paciente evolucionó satisfactoriamente, con inicio de la alimentación a las 6 horas post- operatorias (10), con evolución favorable y alta a las 48 horas con control por consultorio de Cirugía Pediátrica para su seguimiento clínico y ecográfico.

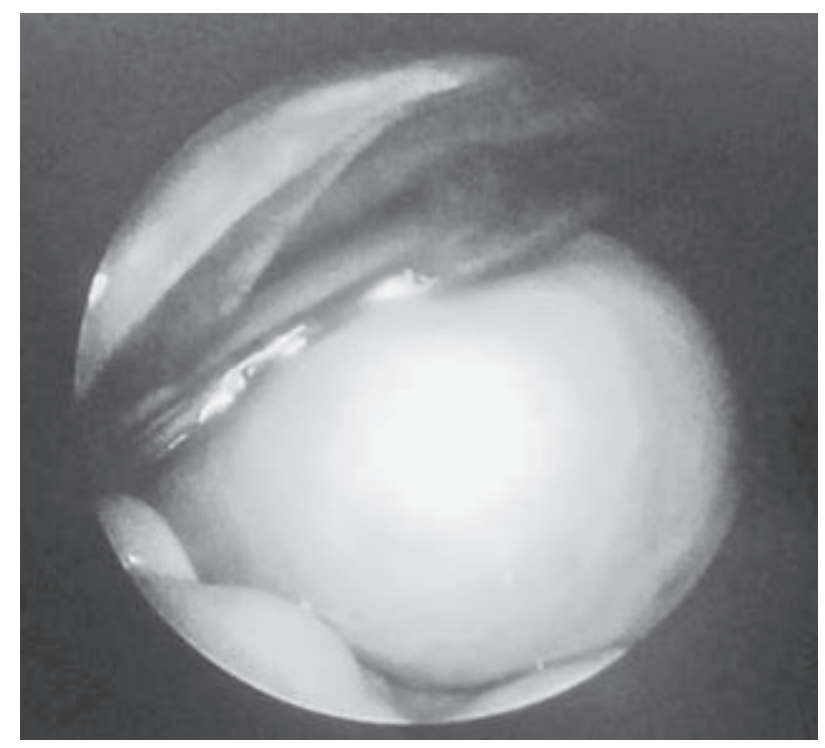

Figura 4. Imagen de quiste anexial derecho hemorrágico a pedículo torcido. 


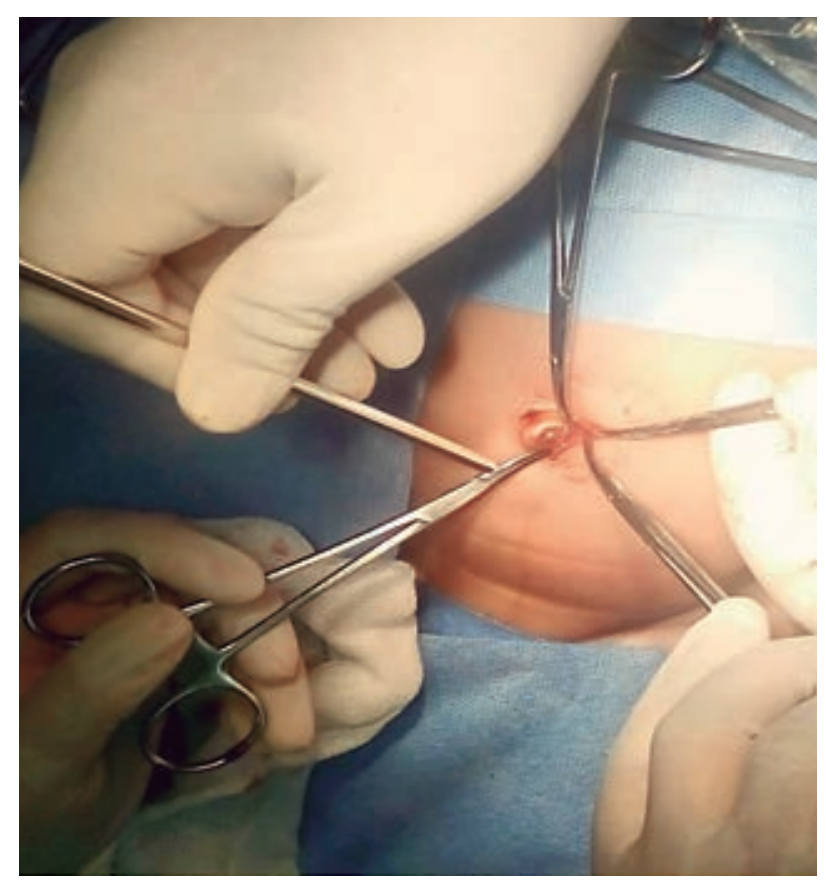

Figura 5. Primer trocar a nivel umbilical.

\section{DISCUSIÓN}

La primera descripción de quiste ovárico en el diagnóstico prenatal fue en 1975 (Valenti et al.), la frecuencia con la cual se detecta esta alteración es cada vez mayor debido a estudios de ultrasonografía prenatal ${ }^{1}$, Los quistes ováricos representan la masa abdominal quística más común en fetos y neonatos femeninos ${ }^{2-8}$. Los folículos ováricos son hallazgos comunes en recién nacidas, encontrándose una incidencia del $32 \%$ al $34 \%$ según reportes de autopsias ${ }^{1}$.

Para el diagnóstico, las imágenes (particularmente La ecografía abdomino-pelvico) permite descartar la mayoría de las patologías y constituye el estudio diagnóstico de primera elección) ${ }^{2}$. El diagnóstico se hace generalmente en el tercer trimestre de gestación con un rango entre 27 y 41 semanas (promedio: 34 semanas) ${ }^{9,10}$. La mayoría de los quistes ováricos se presentan en embarazos sin patología, son simples, unilaterales mayormente y se detectan durante el tercer trimestre ${ }^{8}$. También se utilizan, aunque en mucha menor medida, la tomografía axial computarizada (TAC) y la $\mathrm{RMN}^{4}$. En el recién nacido es difícil establecer el diagnóstico precoz en forma clínica, ya que su sintomatología es tardía e inespecífica ${ }^{8}$. El diagnóstico prenatal de ellos permite un control ecográfico seriado postparto para detectar a tiempo la ocurrencia de esta complicación ${ }^{8}$. El diagnostico ecográfico se basa en la presencia de 4 criterios $^{10:}$ 1) sexo femenino, 2) masa quística abdominal 3) Identificación de riñones y vía urinaria normal, 4) Tracto gastrointestinal normal ${ }^{9}$.

La gran parte de ellos son funcionales, es decir, se forman a partir del tejido ovárico fetal en respuesta al propio estimulo hipofisiario de la $\mathrm{FSH}$, estrógenos maternos y gonadotrofina coriónica placentaria $(\mathrm{HCG})^{8}$. El quiste no complicado tiene pared delgada y es anecoico. Por otro lado el quiste complicado (hemorrágico y por torsión) es de contenido ecogénico; tiene niveles liquido detritos, coágulo retráctil, septos y pared ecogénica (calcificación distrófica asociada a infartos $)^{3}$.

Las complicaciones tienen una incidencia entre el $36 \%$ y el $71 \%$, según las series, siendo las principales: sangrado; ascitis hemorrágica por ruptura de un quiste gigante; peritonitis; torsión; auto amputación; obstrucción intestinal y necrosis; compresión del tracto urinario; compresión de la vena cava; hidramnios, e hipoplasia pulmonar ${ }^{4}$.

El diagnóstico diferencial de una masa abdominal quística en un feto o neonato de sexo femenino incluye: anomalías del tracto gastrointestinal (quistes de duplicación intestinal, quistes mesentéricos, etc.), anomalías del tracto genitourinario (hidrometrocolpos, quistes renales, del ureter, etc.), linfangioma, meningocele anterior, etc ${ }^{2}$.

En muchos centros se recomienda el diagnóstico prenatal y la laparoscopia posnatal para manejo de quistes complicados o muy grandes ${ }^{5}$. Si bien la mayoría de los quistes ováricos corresponden a quistes foliculares, también puede tratarse de quistes de cuerpo lúteo, teca luteínicos, teratomas o cisto adenomas, por lo que se indica siempre resección quirúrgica, si el quiste ovárico tiene aspecto complejo ${ }^{1,3}$.

Algunos autores han tratado de realizar su manejo "in útero", a través de aspiraciones con aguja bajo anestesia local ${ }^{4}$. La torsión puede ocurrir en un ovario normal pero es más probable en quistes grandes (mayores de $4 \mathrm{~cm}$ ), con una incidencia reportada entre el $25 \%$ y el $75 \%{ }^{5}$. Los quistes complejos son altamente predictivos de complicación como torsión o hemorragia intraquística, Mientras algunos autores afirman que el riesgo de torsión se relaciona con el tamaño del quiste, otros consideran que la torsión se relaciona con la longitud del pedículo 4 . Más de 400 casos han sido reportados en la literatura de estos menos del $1 \%$ son sólidos no existen casos reportados de neoplasias malignas ováricas en neonatos ${ }^{8}$.

Para definir la vía del parto, la cesárea debiera ser considerada en el caso de madres gestantes de un feto con un quiste ovárico grande mayor de $8 \times 6 \mathrm{~cm}$ (por riesgo de distocia y ruptura) o la presencia de signos de torsión $n^{3,4}$.

Existe controversia en el manejo postnatal de los quistes ováricos, pues depende de sus características ecográficas y tamaño. Las conductas terapéuticas varían desde el seguimiento ecográfico en el caso de quistes simples menores de $5 \mathrm{~cm}$ hasta la ooforectomia en los complicados con torsión ${ }^{9,11}$. Con el manejo conservador para los quistes menores de $40 \mathrm{~mm}$ de diámetro se realiza con control ecografico seriado cada 3 a 4 semanas $^{4}$, hasta 
los 10 a 12 meses de edad, momento en el que la mayoría de los quistes tienden a resolverse ${ }^{4}$. No se recomienda la aspiración de quistes complejos por el riesgo de hemorragia o peritonitis ${ }^{4}$. Existe controversia respecto al manejo de quistes complejos; algunos recomiendan tratamiento conservador con seguimiento clínico y ecográfico en casos seleccionados: quistes de origen ovárico, niveles de alfafetoproteína y gonadotropina coriónica humana subunidad B normales y ausencia de sintomatología ${ }^{4}$. Otros autores recomiendan tratamiento quirúrgico para disminuir el riesgo de torsión y otras complicaciones, y así asegurar una mayor preservación de tejido ovárico ${ }^{6}$.

En el tratamiento el objetivo es salvar la mayor cantidad de tejido ovárico posible de los quistes ováricos para asegurar el desarrollo puberal y conservación de la fertilidad. Las opciones de tratamiento incluyen: aspiración percutánea o laparoscópica, fenestración o resección laparoscópica, aspiración y resección mediante cirugía mínimamente invasiva y el abordaje por laparotomía (quistectomía, ooforectomía y salpingooforectomía) ${ }^{4}$.El drenaje percutáneo guiado por ecografía se ha realizado con éxito, pero se asocia a recurrencia y no se debe realizar en quistes complejos por los riesgos asociados ${ }^{4}$.

El abordaje laparoscópico ha demostrado ser efectivo y seguro con bajas tasas de complicaciones y mayor preservación de tejido ovárico ${ }^{7,9}$; permite confirmar el diagnóstico en caso de dudas, visualizar ambos ovarios, aspirar o valorar resección del quiste u ooforectomía ${ }^{7-9}$, presenta menos dolor postoperatorio, rápida realimentación y la más baja incidencia de adherencias postoperatorias. Este último punto es especialmente importante en la preservación de la fertilidad en una paciente que potencialmente ha perdido una gónada ${ }^{9}$.

Se recomienda seguimiento ecográfico a todas las pacientes manejadas en forma conservadora para certificar la resolución y la visualización de ambos ovarios ${ }^{8}$.

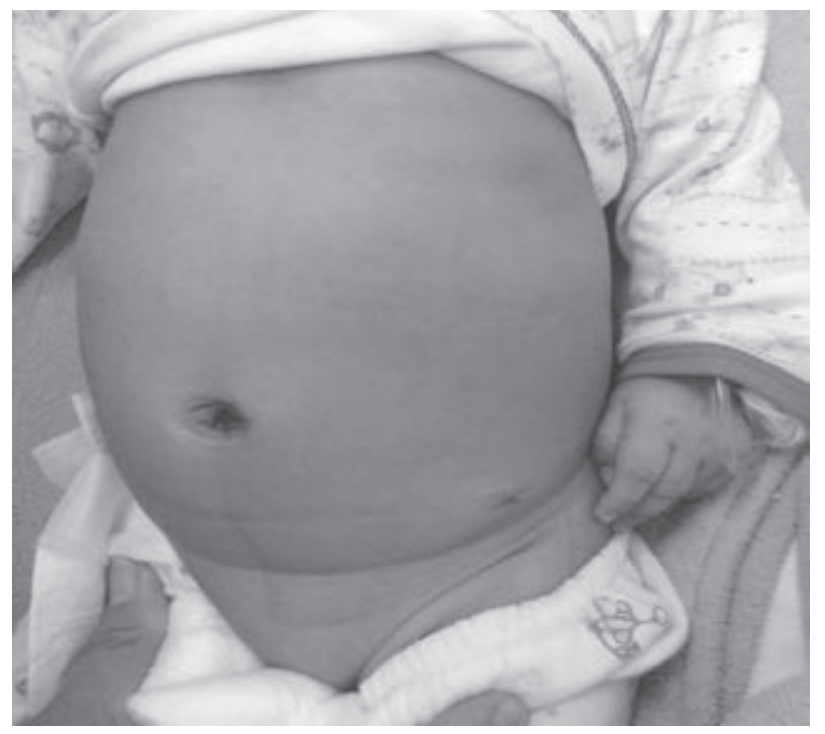

Figura 6. Imagen de evolución postoperatoria.

\section{CONCLUSIÓN}

Se debe considerar la utilidad del diagnóstico prenatal por medio de la ultrasonografía para el diagnóstico precoz de las complicaciones de las masas anexiales, el cual nos permitirá actuar de la manera más oportuna.

Además considerar el abordaje laparoscópico como alternativa en el tratamiento quirúrgico por los beneficios mostrados como su pronto inicio de vía oral, su rápida recuperación y sobretodo el impacto sobre el pronóstico reproductivo de la paciente.

\section{Financiamiento: Autofinanciado.}

Conflicto de interés: Los autores declaran no tener algún conflicto de interés.

\section{REFERENCIAS BIBLIOGRÁFICAS}

1. Valenti A, Kassner G, Yermakov A. Cromb A. Antenatal diagnosis of a fetal ovarian cyst. Am J Obstet Gynecol. 1975;123:216-9

2. Armas AL, Taboada P, Pradillos JM, Rivera LL, Méndez R, Estévez E, Rodríguez P, Bautista A, Varela R. Tratamiento quirúrgico de los quistes ováricos perinatales. Cir Pediatr. 2010; 23: 225-228

3. Nussbaum A R, Sanders R C, Hartman D S, Dudgeon V L, Parmley I H. Neonatal ovarian cysts: sonographic-pathologic correlation pediatric radiology. Radiology. 1988;168(3):817-21

4. Riaño YF, Moreno LA, Beltrán J, López AF. Quistes ováricos neonatales. Presentación de un caso. Rev Colomb Radiol. 2008; 19(2):2431-4

5. Ferro F, lacobelli BD, Zaccara A, Spagnoli A, Trucchi A, Bagolan P. Exteriorization-aspiration minilaparotomy for treatment of neonatal ovarian Cysts. J Pediatr Adolesc Gynecol. 2002.15(4):205-7.

6. Templeman C, Fallat M. Benign ovarian masses. Semin Pediatr Surg. 2005; 14: 93-99

7. Tseng D, Curran T, Silen M. Minimally Invasive Management of the Prenatally Torsed Ovarian Cyst. J Pediatr Surg. 2002; 37: 1467- 1469

8. Rodríguez C, Hurtado E, Jiménez G. Quiste de ovario en una recién nacida: Reporte de un caso. Acta Pediátrica Costarricense 2003;17(1):1-3

9. Bailez M. Masas anexiales en el recién nacido, periodo peripuberal y teratomas maduros del ovario. Enfoque clínico actual, rol y alcances del tratamiento por videolaparoscopia. Rev Med Clin Condes. 2009;20:835 -9

10. Rapin C, Montagne D, Sirinelli Al. Diagnostic of ovarian cysts in the perinatal period and terapeutic implications (20 cases). European Society Of Pediatric Radiology Toronto, 1987;30: 498-502.

11. Sakala Ep, Leon Za, Rouse G. Management of antenatalli diagnosed fetal ovarian cyst. Obst Gynecol Survery. 1991; 46:407-413.

12. Bailez M. Laparoscopia en quistes de ovarios funcionales. Cirugía Endoscópicas en infantes y niños. Edición 2011. Capítulo 104. 771-77 